\title{
A survey to assist in targeting the adults who undertake risky behaviours, know their health behaviours are not optimal and who acknowledge being worried about their health
}

\author{
Anne W Taylor ${ }^{1 *}$, Kay Price ${ }^{2}$ and Simon Fullerton ${ }^{1}$
}

\begin{abstract}
Background: Research indicates that those who are worried about their health are more likely to change their in-appropriate behavioural-related risk factors. A national survey was undertaken to determine adults who correctly perceive and actually undertake in-appropriate behavioural-related risk factors (smoking, physical activity, alcohol intake, fruit and vegetable consumption, weight and psychological distress) and are worried about their health.

Methods: Australian 2010 CATI survey of 3003 randomly selected adults. Perception and self-reported levels of each risk factor, and whether they worried that the level was affecting their health were assessed using univariate and multivariate analyses.

Results: The comparisons between perception of healthy behaviour and actual behaviour varied for each risk factor with $44.1 \%$ of people in the un-healthy weight range and $72.9 \%$ of those eating less than sufficient fruit and vegetables having the perception that their behaviour was healthy. The demographic and other related variables in the multivariate analyse for each risk factor varied considerably. For example the variables in the final multivariate model for smokers who were worried about their risk factor were markedly different to the other risk factor models and 45 to 54 year olds were more likely to be included in the final models for nearly all of the risk factor analyses.

Conclusion: By limiting this analyses to those who are acknowledging (correctly or otherwise) that their perception of behaviour is making their health worse, this study has shown that the profile for each risk factor varies considerably. As such, evidence suggests specific targeted programs are required rather than a broad brush approach.
\end{abstract}

Keywords: Worry, Risk factors, Perception, Australia, Health promotion

\section{Background}

Understanding what makes some people undertake risky behaviours, and others not to, is somewhat perplexing and the basis of much research. Various social cognition theories and models associated with behaviour change (such as stages of change, risk perception transtheoretical model, theory of planned behaviour and health belief model) have been formulated to assist in understanding this phenomenon of undertaking risky

\footnotetext{
* Correspondence: Anne.taylor@adelaide.edu.au

${ }^{1}$ Population Research and Outcome Studies, University of Adelaide, Level 3, 122 Frome Street, Adelaide, South Australia 5000, Australia

Full list of author information is available at the end of the article
}

behaviours [1]. As theorised by many models (see for example [2-4]), acknowledgement that a risk to one's health exists is a procurer to behaviour change. This understanding is based on the principle that if one does not believe they are at risk then they are unlikely to perceive a need to change behaviour. This perceived risk can have a positive relationship on seeking health information [2].

Studies have shown that worry is also related to personal action [5] and has an important role in helping people make decisions. Although worry has negative connotations it is an important step in endorsing protection against harm [5] and motivating action towards 
appropriate health promotion behaviours [6]. Worry has also been shown to be related to the need for an increased amount of information [7] and more positive attitudes towards, and intentions to make, behavioural change [8].

Research has been undertaken on the relationship between perceived risk and worry associated with health effects and the resultant change in risky behaviours $[2,8,9]$. Cameron \& Reece [2] argue that perceived risk and worry 'reflect two parallel systems of information processing'. As argued by many there are two components - a reasoned component (risk) and an emotional component (worry) [9] and that worry can have the strongest predictive nature more than perceived risk $[2,10]$. Others have argued that risk perception is but a judgement about worry [9]. Either way, admitting a perceived risk and having a degree of worry about the situation are highlighting a desire for change, a willingness to listen to information provided and a readiness to take action $[7,11,12]$.

In most theories and models, especially those highlighting cognitive processes, the more one is 'under threat' the more one is likely to accept advice/recommendations [11,13]. Previous research has shown that higher levels of worry predicts a more positive attitude and intention to change but this was more likely to occur for those with the worst-levels of behaviours [8].

In a unique Australian study [14], questions on four key health-related behavioural risk factors (physical activity, smoking status, alcohol consumption, fruit and vegetable consumption as an indication of good nutrition), and two health status outcomes closely related to behaviour and behaviour modification (body mass index (BMI) as an indication of adiposity, and Kessler 10 (K10) as a measure of psychological distress), were assessed together with perception of whether the respondents believed each of their risk factors was at a desired level. Each respondent who perceived they were not at an optimal level were then asked if they worried that the shortfall was affecting their health. This has allowed analysis to be undertaken to assist in determining appropriate interventions based on people's perception of risk, their actual behaviour/risk factor and knowledge of how correct the perception was when compared with actual behaviour.

In the endeavour to change inappropriate or risky behaviours of the population, mass media campaigns and interventions based on increased communication and information exchange are often the preferred intervention strategy $[15,16]$, but improved targeting information is required. If targeted properly, addressing the consumer's needs, interests and motives, the chance of a successful behaviour change is enhanced [17]. While socio-demographic data provide meaningful evidence of who should be targeted, demographic characteristics are limited in their ultimate changeability [1]. Additional evidence, such as the variables provided in this analysis, are more readily amenable to change hence provide important evidence for health promotion experts.

In this paper we highlight the different profile of risk behaviours and their relationship to perception of risk and actual behaviour. We hypothesise that people who are worried about their health are more likely to change their unhealthy behaviours [13] and as such we provide, for each of the six key risk factors, a multivariate analysis of demographic, socio-economic and other healthrelated variables.

\section{Method}

A 'Novel approach to Influencing Self Care' project [14] was funded through the Australian Federal Government Sharing Health Care Initiative. The aim of the mixed methods study was to inform health professionals and policy makers of the best strategies to support targeted groups of people with chronic conditions to more effectively manage their health. Data used in the analysis of this paper were obtained from a national survey - Stage 3 of the 'Novel approach to Influencing Self Care' study. The questionnaire was developed from previous stages of the study that included detailed profiles of respondents of the North West Adelaide Health Cohort Study (Stage 1) [18] and semi-structured interviews (Stage 2) [14]. The national survey (Stage 3) - the focus of this stand-alone analysis - was designed to gather information about what was driving decision-making on an everyday basis for people living with and without chronic conditions, as well as what risky behaviours they engage in and if they are aware of this risk. While the survey was used to explore a range of other healthrelated issues, only selected variables from the national survey were used in these analyses.

\section{Data collection}

All households in Australia with a connected telephone and the telephone number listed in the Australian Electronic White Pages (EWP) were eligible for selection. Within each household contacted, a random person (the person, aged 18 years or over, who was last to have a birthday) was selected. There was no replacement for non-contactable persons. On average, interviews took 15 minutes to complete. In an endeavour to increase response rates, a letter outlining the purpose of the study was sent to selected households. Data collection was undertaken by a contracted agency using trained interviewers in April and May, 2010. Interviews were conducted using Computer Assisted Telephone Interview (CATI) methodology. 
A minimum of 10 call-backs were made to telephone numbers selected for interview. Different times of the day or evening were scheduled for each call-back. If the person could not be interviewed immediately they were re-scheduled for interview at a time suitable to them. Replacement interviews for persons who could not be contacted or interviewed were not permitted. Ten percent of each interviewer's work was randomly selected for validation by the supervisor.

An initial sample of 10,000 telephone numbers was drawn. Sample loss of 3,138 occurred due to nonconnected numbers $(n=2,641)$, non-residential number $(n=276)$, fax/modem connections $(n=206)$ and ineligible households $(n=15)$. The overall sample response rate was $43.8 \%$.

\section{Questionnaire}

Respondents were initially asked their perception of their risk factor (do you think you exercise enough; do you eat a balance diet; do you drink more alcohol than is good for you or than you should; do you think you are overweight, underweight, OK weight; and do you think you worry or stress more than is good for you). If they answered negatively for exercise or diet, positively for alcohol or stress, or responded underweight or overweight regarding weight, they were then asked whether they worried about it (eg does it worry you that not exercising enough may affect your health). Current smokers and ex-smokers were also asked if they worry that their previous/current smoking could affect their health.

Risk factor questions were asked towards the end of the questionnaire and were: how many times a week physical activity of at least 30 minutes was undertaken (insufficient activity defined as less than 150 minutes of physical activity per week), how many serves of vegetables and fruit per day consumed (with respondents deemed to not be eating the required number if they reported less than five serves of vegetables or two serves of fruits per day) [19]; how often and on how many days alcohol was consumed (with risky levels for men, defined as consuming seven or more drinks on any one occasion or alcohol consumption four or more times per week; for women, defined as consuming five or more drinks on any one occasion or alcohol consumption four or more times per week) [20]; BMI (self-reported height and weight) [21]; psychological distress using the Kessler 10 (by receiving a score of 22 or higher on the Kessler 10 instrument) [22]; and smoking status. These questions have all been tested for validity and reliability in the Australian CATI setting [23].

The value of this study is the wide range of ancillary health-related questions asked in the survey. These other questions included in the analysis were based on issues brought up in the focus group discussions and these covered three key concepts - 'perception of health' and 'health service use' and 'health action'. Perceptions of health questions were overall health status, whether life was affected by health conditions, how often pain stopped activity, how often the respondent had enough energy, how often they felt angry about their health, and whether they cared about their health. Health service use questions were use of complementary and alternative medicines, doctor visits in the previous year, and other health professional visits in the previous year. Health action related questions were how often they had to adjust pace because of health, whether they did things to reduce their stress, whether they tried to stay connected with people, and if they had ever used trial and error. 'Trial and error' is a decision-making strategy that is personal and purposefully implemented to assist an individual to make sense of what is/is not possible for them to do in everyday circumstances. Decisions people make are not necessarily made being mindful of how their decisions will impact on their future health status [24].

Demographic questions asked included age, sex, marital status, work status, country of birth, highest education level obtained, housing status, and annual household income.

\section{Statistical methods}

Raw data from the CATI system were analysed using SPSS Version 18.0 and Microsoft Excel. The data were weighted by age and sex to reflect the structure of the Australian population 18 years and over using the Australian Bureau of Statistics 2006 Estimated Residential Population. The weights reflect unequal sample inclusion probabilities and compensate for differential non-response.

Initially, a prevalence estimate for each risk factor was produced for the whole sample. In addition, a comparions between actual risk factor status and perceived risk (healthy, unhealthy) was undertaken using data from all participants. As the focus of this paper was on perceived unhealthy behaviours, no further analyses were undertaken for those whose perception was that they were undertaking the behaviour at a healthy level. Actual risk factor status was then assessed against worry status (worried, not worried). To determine the population most likely to change their behaviour (based on the fact that they believe they are at risk, they actually are in the risky category plus they are worried about the affect of the risk factor on their health - our target population), univariable analyses using chi-square tests were employed to compare differences for each of the six behaviours/risk factors. Six separate multivariable logistic regression models were subsequently developed. As recommended by Hosmer and Lemeshaw [25], all 
Table 1 Socio-economic and demographic characteristics of respondents, Australia, 2010

Demographic and socioeconomic profile of respondents

Sex

Male

Female

$65+$ years

55 to 64 years

45 to 54 years

35 to 44 years

18 to 34 years

Number of adults in household aged 18+ years

One

Two

Three or more

Country of birth*

Australia

UK / Ireland

Other

Aboriginal or Torres Strait Islander

No

Aboriginal / Torres Strait Islander

Family structure

Family and children

Adult living alone

Adult living with partner - no children

Adults living together - related / unrelated

Other

Marital status

Never Married

Married/living with partner

Separated/divorced

Widowed

\section{Employment status}

Full time employed

Part time employed

Unemployed

Economically inactive (Home duties, student, retired, unable to work, other)

Highest education level obtained

No schooling to secondary

Trade, certificate, diploma

Degree or higher

\section{Undertake volunteer activities}

Yes

No
Age group
$\%$

48.7

51.3

1540

528

17.6

14.4

18.6

19.6

29.9

332

11.1

56.2

32.7

2349

184

469

2287

58

1574

284

769

343

30

651

1999

189

147

1287

564

105

1046

78.2

6.1

15.6

97.4

2.5

52.4

9.5

25.6

11.4

1.0

21.8

67.0

6.3

4.9

42.9

18.8

3.5

34.8

46.1

25.2

27.1

33.9

66.1
$(95 \% \mathrm{Cl})$

(46.9-50.5)

(49.5-53.1)

(16.3-19.0)

(13.2-15.7)

(17.2-20.0)

(18.2-21.1)

(28.3-31.5)

(10.0-12.2)

(54.4-58.0)

(31.1-34.4)

(76.7-79.6)

(5.3-7.0)

(14.4-16.9)

(74.6-77.7)

(1.5-2.5)

(50.6-54.2)

(8.5-10.6)

(24.1-27.2)

(10.3-12.6)

(0.7-1.4)

(20.3-23.3)

(65.2-68.6)

(5.5-7.2)

(4.2-5.8)

(41.1-44.6)

(17.4-20.2)

(2.9-4.2)

(33.2-36.6)

(44.3-47.9)

(23.7-26.8)

(25.5-28.7)
(32.2-35.6)

(64.4-67.8) 
Table 1 Socio-economic and demographic characteristics of respondents, Australia, 2010 (Continued)

\begin{tabular}{|c|c|c|c|}
\hline \multicolumn{4}{|l|}{ Provide long term care } \\
\hline Yes & 771 & 25.7 & $(24.2-27.3)$ \\
\hline No & 2232 & 74.3 & $(72.7-75.8)$ \\
\hline \multicolumn{4}{|l|}{ Gross annual household income } \\
\hline$\$ 80,000$ or more & 1136 & 37.8 & $(36.1-39.6)$ \\
\hline$\$ 40,001-\$ 80,000$ & 698 & 23.2 & $(21.8-24.8)$ \\
\hline Up to $\$ 40,000$ & 575 & 19.1 & $(17.8-20.6)$ \\
\hline Not stated & 594 & 19.8 & $(18.4-21.3)$ \\
\hline \multicolumn{4}{|l|}{ Household money situation } \\
\hline Spending more money than receive & 125 & 4.2 & $(3.5-4.9)$ \\
\hline Just enough money to get through to next pay day & 549 & 18.3 & $(16.9-19.7)$ \\
\hline Some money left over each week but spend it & 184 & 6.1 & $(5.3-7.0)$ \\
\hline Save a bit every now and then & 1441 & 48.0 & $(46.2-49.8)$ \\
\hline Save a lot & 590 & 19.6 & $(18.3-21.1)$ \\
\hline Don't know & 87 & 2.9 & $(2.4-3.6)$ \\
\hline Refused & 27 & 0.9 & $(0.6-1.3)$ \\
\hline \multicolumn{4}{|l|}{ Dwelling type* } \\
\hline Owned or being purchased & 2458 & 82.1 & $(80.7-83.4)$ \\
\hline Rented from government housing & 86 & 2.9 & $(2.3-3.5)$ \\
\hline Rented privately & 398 & 13.3 & $(12.1-14.6)$ \\
\hline Community housing / Retirement village/other & 52 & 1.7 & $(1.3-2.3)$ \\
\hline Total & 3003 & 100.0 & \\
\hline
\end{tabular}

Note: The weighting of the data can result in rounding discrepancies or totals not adding. *Don't know category not included.

variables with a p-value $<0.25$ at the univariable level, were included in the initial multivarialbe model in order to ascertain independently associated factors. Final models were obtained using backward stepwise elimination of non-significant variables based on the log likelihood ratio tests. A p-value less than 0.05 was regarded as statistically significant.

The research was carried out following approval from the University of South Australia Human Research Ethics Committee, which are guided by the Australian code for the responsible conduct of research \& the National Statement on Ethical Conduct in Human Research 2007.

\section{Results}

Overall 3001 interviews were conducted with 48.7\% being with males. The mean age was 44.9 years (SD 15.1). Table 1 contains the demographic characteristics of the complete sample.

Table 2 details, for the whole sample, the overall prevalence estimates associated with each risk factor. In total, $18.2 \%$ of respondents had at least four of these six risk factors.

Table 3 highlights, for the whole sample, the actual risk factor category by the perception of risk (healthy or unhealthy) associated with individual behaviour. The proportion in the correct/normal risk category and whose perception matched, ranged from $91.1 \%$ for fruit and vegetable consumption to $46.4 \%$ for psychological distress. Conversely, those who were actually in the risk category but whose perception was incorrect (believing the risk factor was in the healthy range) varied from $11 \%$ for psychological distress to $72.9 \%$ for fruit and vegetable consumption meaning that over $70 \%$ of respondents believed they were eating a balanced healthy diet when their actual consumption of fruit and vegetables (as an indicator of a healthy diet) was less than the recommended two and five serves of fruit and vegetables per day. Proportions ranged from $27.1 \%$ for inadequate serves of fruit and vegetable consumption to $89.0 \%$ for psychological distress for those in the risky category, whose perception and actual behaviour matched. Smoking is not included in this table as questions related to smoking were limited to current smoking and worry status, rather than perception of risk, with all current and ex-smokers deemed to be at risk.

Table 4 highlights the worry status and risk factor status only for those respondents who believe their risk profile is not optimal (that is, regardless of their actual behaviour, their perception was that they were undertaking the actual behaviour at an unhealthy level (those in 
Table 2 Prevalence estimates associated with each risk factor, Australia, 2010

\begin{tabular}{|c|c|c|c|}
\hline & $\mathrm{n}$ & $\%$ & $(95 \% \mathrm{Cl})$ \\
\hline \multicolumn{4}{|l|}{ BMI } \\
\hline Underweight & 79 & 3.0 & $(2.4-3.8)$ \\
\hline Normal & 1059 & 40.5 & $(38.6-42.4)$ \\
\hline Overweight & 924 & 35.3 & $(33.5-37.2)$ \\
\hline Obese & 553 & 21.1 & $(19.6-22.7)$ \\
\hline \multicolumn{4}{|l|}{ Fruit and vegetable consumption } \\
\hline At least $2 \& 5$ serves per day & 266 & 8.9 & $(7.9-9.9)$ \\
\hline Less than $2 \& 5$ serves per day & 2737 & 91.1 & $(90.1-92.1)$ \\
\hline \multicolumn{4}{|l|}{ Physical activity } \\
\hline Sufficient activity & 1592 & 53.1 & $(51.3-54.8)$ \\
\hline No activity/activity but not sufficient/don't know & 1409 & 46.9 & $(45.2-48.7)$ \\
\hline \multicolumn{4}{|l|}{ Smoking } \\
\hline Non-smoker & 1390 & 46.3 & $(44.5-48.1)$ \\
\hline Ex-smoker & 1084 & 36.1 & $(34.4-37.8)$ \\
\hline Current smoker & 529 & 17.6 & $(16.3-19.0)$ \\
\hline \multicolumn{4}{|l|}{ Short term alcohol risk } \\
\hline Non-drinker & 685 & 22.8 & $(21.3-24.4)$ \\
\hline Low risk & 1463 & 48.8 & $(47.0-50.5)$ \\
\hline Risky & 725 & 24.2 & $(22.7-25.7)$ \\
\hline High risk & 128 & 4.3 & $(3.6-5.1)$ \\
\hline \multicolumn{4}{|l|}{ Psychological distress } \\
\hline Low & 1872 & 62.6 & $(60.8-64.3)$ \\
\hline Moderate & 762 & 25.5 & $(23.9-27.1)$ \\
\hline High & 256 & 8.6 & $(7.6-9.6)$ \\
\hline Very high & 101 & 3.4 & $(2.8-4.1)$ \\
\hline \multicolumn{4}{|l|}{ Number of risk factors } \\
\hline None & 53 & 2.0 & $(1.6-2.7)$ \\
\hline One & 382 & 14.7 & $(13.3-16.1)$ \\
\hline Two & 810 & 31.1 & $(29.3-32.9)$ \\
\hline Three & 884 & 33.9 & $(32.1-35.8)$ \\
\hline Four & 386 & 14.8 & $(13.5-16.3)$ \\
\hline Five & 76 & 2.9 & $(2.3-3.6)$ \\
\hline Six & 14 & 0.5 & $(0.3-0.9)$ \\
\hline Total & 3003 & 100.0 & \\
\hline
\end{tabular}

the right hand column of Table 3)). When comparing those who have the risk factor significant differences were apparent for all risk factors, except for short-term alcohol risk. The proportion who are actually in the normal range but who still worry about the risk factor affecting their health ranged from $43.4 \%$ for normal BMI to $98.6 \%$ of those eating two and five serves of fruits and vegetables per day. The proportion who were at risk and correctly worried about it (our target population) ranged from $48.0 \%$ for alcohol to $92.2 \%$ for psychological distress.
Table 5 highlights the results of the multivariate analysis for all six risk factors with each column showing the odds associated with the risk factor for respondents who were worried about the individual risk factor. There was a range of conflicting results for different risk factors. For example, being married or living with a partner meant that you were less likely to have high psychological distress (OR 0.65) but more likely to have an increased BMI (OR 1.64). This pattern was also found for example for work status (with increased risk for physical inactivity and alcohol for the unemployed and 
Table 3 Risk factor perception versus actual behaviour, Australia, 2010

\begin{tabular}{|c|c|c|c|c|c|c|}
\hline \multirow[b]{2}{*}{ Actual measure } & \multicolumn{3}{|c|}{ Perception - healthy } & \multicolumn{3}{|c|}{ Perception - unhealthy } \\
\hline & $\mathrm{n}$ & $\%$ & $(95 \% \mathrm{Cl})$ & n & $\%$ & $(95 \% \mathrm{Cl})$ \\
\hline \multicolumn{7}{|l|}{ BMI } \\
\hline Normal & 958 & 90.5 & $(88.6-92.1) \uparrow$ & 101 & 9.5 & $(7.9-11.4) \downarrow$ \\
\hline Underweight /Overweight / Obese & 688 & 44.1 & $(41.7-46.6) \downarrow$ & 870 & 55.9 & $(53.4-58.3) \uparrow$ \\
\hline \multicolumn{7}{|l|}{ Fruit and vegetable consumption } \\
\hline Recommended amount & 243 & 91.1 & $(87.1-94.0) \uparrow$ & 24 & 8.9 & $(6.0-12.9) \downarrow$ \\
\hline Less than recommended amount & 1995 & 72.9 & $(71.2-74.5) \downarrow$ & 742 & 27.1 & $(25.5-28.8) \uparrow$ \\
\hline \multicolumn{7}{|l|}{ Physical activity } \\
\hline Sufficient activity & 1003 & 63.0 & $(60.6-65.3) \uparrow$ & 589 & 37.0 & $(34.7-39.4) \downarrow$ \\
\hline No activity/activity but not sufficient/don't know & 364 & 25.9 & $(23.6-28.2) \downarrow$ & 1044 & 74.1 & $(71.8-76.4) \uparrow$ \\
\hline \multicolumn{7}{|l|}{ Short term alcohol risk } \\
\hline Non-drinker/no risk & 1694 & 78.9 & $(77.1-80.5) \uparrow$ & 454 & 21.1 & $(19.5-22.9) \downarrow$ \\
\hline Risky/high risk & 285 & 33.4 & $(30.3-36.6) \downarrow$ & 568 & 66.6 & $(63.4-69.7) \uparrow$ \\
\hline \multicolumn{7}{|l|}{ Psychological distress } \\
\hline Low/ Moderate & 1223 & 46.4 & $(44.5-48.4) \uparrow$ & 1411 & 53.6 & $(51.6-55.5) \downarrow$ \\
\hline High Nery high & 39 & 11.0 & $(8.1-14.6) \downarrow$ & 318 & 89.0 & $(85.4-91.9) \uparrow$ \\
\hline
\end{tabular}

$\uparrow \downarrow$ Statistically significantly higher or lower than other group $(p<0.05)$.

lower risk for BMI for the unemployed), dwelling type (increased risk for smoking and psychological distress and lower risk for physical inactivity for those renting from the government), household income (higher risk for BMI and psychological distress and lower risk for physical activity for the middle income group), visits to a doctor in the last year (increased risk for BMI and lower risk for smoking), visits to other health professional in the last year (with increased risk for fruit and vegetable consumption and alcohol and lower risk for smoking) and use of trial and error (with increased risk for BMI and fruit and vegetable consumption and lower risk for

Table 4 Risk factors status (for those whose perception is of unhealthy behaviour), by worry status, Australia, 2010

\begin{tabular}{|c|c|c|c|c|c|c|}
\hline \multirow[b]{2}{*}{ Actual measure } & \multicolumn{3}{|c|}{ Worried } & \multicolumn{3}{|c|}{ Not worried } \\
\hline & $\mathrm{n}$ & $\%$ & $(95 \% \mathrm{Cl})$ & $\mathbf{n}$ & $\%$ & $(95 \% \mathrm{Cl})$ \\
\hline \multicolumn{7}{|l|}{ BMI } \\
\hline Normal & 44 & 43.4 & $(34.2-53.2) \downarrow$ & 57 & 56.6 & $(46.8-65.8) \uparrow$ \\
\hline Underweight /Overweight / Obese & 612 & 70.3 & $(67.2-73.3) \uparrow$ & 258 & 29.7 & $(26.7-32.8) \downarrow$ \\
\hline \multicolumn{7}{|l|}{ Fruit and vegetable consumption } \\
\hline Correct amount & 23 & 98.6 & $(83.7-99.9)$ & 1 & 1.4 & - \\
\hline Less than correct amount & 564 & 76.1 & $(72.9-79.0) \downarrow$ & 178 & 23.9 & $(21.0-27.1) \uparrow$ \\
\hline \multicolumn{7}{|l|}{ Physical activity } \\
\hline Sufficient activity & 439 & 74.5 & $(70.9-77.9) \downarrow$ & 150 & 25.5 & $(22.1-29.1) \uparrow$ \\
\hline No activity/activity but not sufficient/don't know & 849 & 81.3 & $(78.8-83.5) \uparrow$ & 196 & 18.7 & $(16.5-21.2) \downarrow$ \\
\hline \multicolumn{7}{|l|}{ Smoking } \\
\hline Non/ex-smoker & 525 & 67.5 & $(64.2-70.7) \downarrow$ & 252 & 32.5 & $(29.3-35.8) \uparrow$ \\
\hline Current smoker & 421 & 79.6 & $(75.9-82.8) \uparrow$ & 108 & 20.4 & $(17.2-24.1) \downarrow$ \\
\hline \multicolumn{7}{|l|}{ Short term alcohol risk } \\
\hline Non-drinker/no risk & 230 & 50.6 & $(46.0-55.2)$ & 224 & 49.4 & $(44.8-54.0)$ \\
\hline Risky/high risk & 272 & 48.0 & $(43.9-52.1)$ & 296 & 52.0 & $(47.9-56.1)$ \\
\hline \multicolumn{7}{|l|}{ Psychological distress } \\
\hline Low/ Moderate & 960 & 68.0 & $(65.5-70.4) \downarrow$ & 451 & 32.0 & $(29.6-34.5) \uparrow$ \\
\hline High Nery high & 295 & 92.9 & $(89.5-95.2) \uparrow$ & 23 & 7.1 & $(4.8-10.5) \downarrow$ \\
\hline
\end{tabular}

$\uparrow \downarrow$ Statistically significantly higher or lower than other group $(p<0.05)$. 
Table 5 Multivariate analysis of factors associated with participants who worry about their behaviour and who thought their behaviour unhealthy, by risk factor, Australia, 2010

\begin{tabular}{|c|c|c|c|c|c|c|}
\hline & $B M I$ & $F \& V$ & $P A$ & Smoking & $\begin{array}{l}\text { Short term } \\
\text { alcohol risk }\end{array}$ & $\begin{array}{l}\text { High Psychological } \\
\text { distress }\end{array}$ \\
\hline $\begin{array}{l}\text { Number of people in each } \\
\text { behaviour/worry group }\end{array}$ & $612 / 971$ & $564 / 765$ & $849 / 1633$ & $421 / 1306$ & $272 / 1022$ & $295 / 1728$ \\
\hline $\begin{array}{l}\% \text { in each behaviour/worry } \\
\text { group }(95 \% \mathrm{Cl})\end{array}$ & $63.0(60.0-66.0)$ & $73.7(70.5-76.7)$ & $51.9(49.5-54.4)$ & $32.2(29.7-34.8)$ & $26.7(24.0-29.5)$ & $17.1(15.4-18.9)$ \\
\hline \multicolumn{7}{|l|}{ Sex } \\
\hline Male & & & & & 1.00 & \\
\hline Female & & & & & $1.41(0.04)$ & \\
\hline \multicolumn{7}{|l|}{ Age } \\
\hline $65+$ years & 1.00 & 1.00 & 1.00 & 1.00 & 1.00 & 1.00 \\
\hline 55 to 64 years & $1.82(0.02)$ & $2.04(0.13)$ & $1.28(0.29)$ & $2.80(<0.01)$ & $1.35(0.39)$ & $1.61(0.17)$ \\
\hline 45 to 54 years & $2.21(<0.01)$ & $3.30(0.01)$ & $1.30(0.25)$ & $3.94(<0.01)$ & $2.44(0.01)$ & $2.15(0.03)$ \\
\hline 35 to 44 years & $1.48(0.12)$ & $2.23(0.07)$ & $1.74(0.02)$ & $6.18(<0.01)$ & $1.71(0.13)$ & $2.17(0.03)$ \\
\hline 18 to 34 years & $1.47(0.13)$ & $1.88(0.15)$ & $1.35(0.19)$ & $8.60(<0.01)$ & $1.80(0.06)$ & $3.91(<0.01)$ \\
\hline \multicolumn{7}{|l|}{ Marital status } \\
\hline Never Married & 1.00 & 1.00 & 1.00 & & & 1.00 \\
\hline Married/living with a partner & $1.64(0.01) \uparrow$ & $0.89(0.63)$ & $0.66(0.01)$ & & & $0.65(0.04)$ \\
\hline Separated/divorced & $1.02(0.95)$ & $0.43(0.02)$ & $0.80(0.41)$ & & & $0.98(0.96)$ \\
\hline Widowed & $1.37(0.40)$ & $1.10(0.88)$ & $0.89(0.7)$ & & & $0.61(0.29)$ \\
\hline \multicolumn{7}{|l|}{ Education } \\
\hline No schooling to secondary & & 1.00 & 1.00 & 1.00 & 1.00 & \\
\hline Trade, certificate, diploma & & $1.09(0.69)$ & $1.23(0.12)$ & $0.68(0.02)$ & $0.61(0.01)$ & \\
\hline Degree or higher & & $2.06(0.01)$ & $1.53(<0.01)$ & $0.73(0.10)$ & $0.93(0.70)$ & \\
\hline \multicolumn{7}{|l|}{ Work status } \\
\hline Full time employed & 1.00 & & 1.00 & 1.00 & 1.00 & 1.00 \\
\hline Part time employed & $0.87(0.38)$ & & $1.15(0.33)$ & $0.84(0.32)$ & $0.78(0.30)$ & $1.18(0.46)$ \\
\hline Unemployed & $0.32(0.01)$ & & $2.86(<0.01)$ & $0.83(0.62)$ & $3.33(0.01)$ & $1.12(0.74)$ \\
\hline Economically inactive & $1.06(0.71)$ & & $1.24(0.15)$ & $0.60(0.01)$ & $1.48(0.05)$ & $1.80(<0.01)$ \\
\hline \multicolumn{7}{|l|}{ Dwelling } \\
\hline Owned or being purchased & & & 1.00 & 1.00 & & 1.00 \\
\hline Rented from Government Housing & & & $0.36(0.01)$ & $2.32(0.01)$ & & $3.08(<0.01)$ \\
\hline Rented Privately & & & $1.19(0.28)$ & $2.29(<0.01)$ & & $1.02(0.93)$ \\
\hline Community/Retirement Village/ Other & & & $1.54(0.31)$ & $0.78(0.72)$ & & $5.80(<0.01)$ \\
\hline \multicolumn{7}{|l|}{ Country of Birth } \\
\hline Australia & & 1.00 & & & & \\
\hline UKIreland & & $0.55(0.19)$ & & & & \\
\hline Other & & $0.59(0.03)$ & & & & \\
\hline \multicolumn{7}{|l|}{ Household annual income } \\
\hline$>\$ 80,000$ & 1.00 & & 1.00 & & & 1.00 \\
\hline$\$ 40,001-\$ 80,000$ & $1.81(<0.01)$ & & $0.54(<0.01)$ & & & $1.60(0.02)$ \\
\hline$<\$ 40,000$ & $1.66(0.01)$ & & $0.65(0.02)$ & & & $1.07(0.79)$ \\
\hline Not stated & $1.85(<0.01)$ & & $0.55(<0.01)$ & & & $0.83(0.45)$ \\
\hline
\end{tabular}


Table 5 Multivariate analysis of factors associated with participants who worry about their behaviour and who thought their behaviour unhealthy, by risk factor, Australia, 2010 (Continued)

Overall quality of life

Excellent/very good

Good

Fair/poor

Had complementary and alternative medicine

No/don't know

Yes

Life affected by health

Activities limited/bedridden most of the time

No problems /Can work \& live normally

day to day

How often pain stops you doing

what you want

Always

1.00

Sometimes

Not/hardly at all

$1.90(0.11)$

$2.84(0.01)$

1.00

$1.23(0.09)$

1.00

1.00

$1.55(0.01)$

$1.15(0.37)$

$1.44(0.05)$

$2.24(<0.01)$

1.00

1.00

1.00

$1.85(<0.01)$

$1.56(<0.01)$

$1.49(0.02)$

1.00

$1.55(0.02)$

1.00

$1.65(0.04)$

$1.61(0.07)$

$1.99(0.02)$
1.00

$0.53(0.04)$

$0.46(0.02)$

1.00

$0.78(0.31)$

$0.96(0.87)$

$0.34(<0.01)$

$1.00 \quad 1.00$

$0.63(<0.01) \quad 1.72(<0.01)$

$0.39(<0.01) \quad 0.92(0.75)$

$0.41(<0.01) \quad 0.98(0.93)$

1.00
$1.47(\mathbf{0 . 0 4 )}$

1.00

$2.10(<0.01)$

$0.99(0.97)$

A little/none of the time

How often have to adjust pace because of health

A little/none of the time

1.00

1.00

1.00

some of the time

$1.35(0.03)$

$1.54(0.03)$

$1.56(0.02)$

$0.75(0.11)$

$2.10(0.01)$

$0.49(0.01)$

1.00

1.00

$1.83(0.01)$

No

Try and stay connected to people

Yes/sometimes

1.00

No 
Table 5 Multivariate analysis of factors associated with participants who worry about their behaviour and who thought their behaviour unhealthy, by risk factor, Australia, 2010 (Continued)

\begin{tabular}{|c|c|c|c|c|c|c|}
\hline \multicolumn{7}{|l|}{ Ever used trial and error } \\
\hline No/ don't know/refused & 1.00 & 1.00 & & & 1.00 & \\
\hline Yes/sometimes & $1.71(<0.01)$ & $2.23(0.05)$ & & & $0.67(0.03)$ & \\
\hline \multicolumn{7}{|c|}{$\begin{array}{l}\text { How often do you feel angry about } \\
\text { your health }\end{array}$} \\
\hline A little/none of the time & & 1.00 & 1.00 & 1.00 & & 1.00 \\
\hline Some of the time & & $2.23(<0.01)$ & $1.28(0.09)$ & $1.55(0.02)$ & & $2.41(<0.01)$ \\
\hline All/most of the time & & $1.26(0.53)$ & $2.12(<0.01)$ & $2.37(0.01)$ & & $7.12(<0.01)$ \\
\hline \multicolumn{7}{|c|}{ Do you care about your health } \\
\hline A little/none of the time & 1.00 & & & 1.00 & & \\
\hline Some of the time & $1.43(0.21)$ & & & $2.09(0.02)$ & & \\
\hline All/most of the time & $1.89(0.01)$ & & & $1.11(0.69)$ & & \\
\hline
\end{tabular}

alcohol). Education level was also different across risk factors with increased odds for those with a degree or higher and who are not eating enough fruit and vegetables (OR 2.06) and for insufficient physical activity (OR 1.53) whilst those with trade, certificate or diploma level of education had a lower risk for smoking (OR 0.68) and short term alcohol risk (OR 0.61).

\section{Discussion}

The results of these analyses highlight firstly, the relationship between actual behaviour and perception of behaviour with large proportions of the population having an incorrect perception of their risk. Secondly, the analysis highlighted the proportions of people who worry about their health as a result of not undertaking the correct behaviour with substantial proportions of this population reporting high levels of worry. The results of the multivariable analyses highlight the similarities and dissimilarities between a wide range of demographic, socioeconomic and other related variables for the six key behavioural indicators. The multivariate analysis concentrated on those whose perception is that they undertake unhealthy behaviours, based on the premise that this perception is required before any behaviour change can be undertaken. If a stage of change model was employed these people would be in the contemplation and preparation stages [1]. What this analysis has shown is that there are clear demographic and health-related variables that are different between the groups who are, and are not, worried about the health effects of their actions.

One of the most striking features of the multivariate analyses was the markedly different profiles for different risk factors. Noticeable in these results is the 'different' profile for smokers (less likely to fit with the other risk factors) and the range of positive associations with BMI. This highlights the fact that campaigns need to be targeted differently depending upon the profile of the population who are most likely to act upon the message. As argued by others [26,27], the tailoring of specific messages to specific groups is an important endeavour to counteract the broad, population-wide, non-specific messages commonly used. There is a need to look past the demographic areas of research so that additional detail on the broader life and health context details are provided.

The most striking commonalities across the behaviours was age with all risk factors associated with at least one age group. The 45 to 54 year olds were most likely to have increased odds for each risk factor. This highlights the middle age groups as key targets for interventions, with those who are in the risk categories and are worried about the effect the risk factor is having on their health, being perfect targets for interventions. Other studies have found that midlife is an important time of life to make positive behavioural changes [28-30]. Interestingly, a trend was apparent for smoking and psychological distress with each younger age group more likely to have higher odds indicating that the young smokers and the younger persons with high levels of psychological distress are prime targets for interventions.

While research has highlighted the socio-economic differences apparent in risk behaviours with lower income groups more likely to be smokers [31], undertake less exercise [32], and have higher rates of obesity [33], this analysis showed that the relationship is not necessarily as straight forward as it seems. While our only measure of socio-economic status was annual household income, it was the middle household income level ( $\$ 40,000$ to $\$ 80,000$ per year) who were more likely to be in the final models for BMI and high psychological distress indicting that campaigns targeting middle income levels for this risk factor should be considered. The lower income level $(<\$ 40,000)$ was also statistically significantly more likely to be included in the BMI 
model indicting that for BMI both lower income groups are also targets for intervention. In contrast, the middle income level was statistically significantly lower for physical inactivity indicting that this income group were less likely to be worried about their inactivity. No such clear message was apparent in our analysis for fruit and vegetable, alcohol and smoking with household income not included in the final models. Again the need for more detailed, topicspecific interventions are warranted.

A visit to a doctor was a variable included in the final model for BMI highlighting the important opportunity the general practitioner has in influencing these adults. Not surprisingly, smokers were significantly less likely to visit a doctor 10 or more times in the past year. This pattern was repeated for visits to other health professionals with smokers statistically significantly less likely to visit other health professionals while those at risk for low fruit and vegetable consumption and alcohol were statistically significantly more likely to visit other health professionals at least one to four times per year. Previous research has highlighted the important role that general practitioners and other medical specialists have in encouraging and influencing positive behavioural change of their patients [34,35], although concerns have been expressed on how successful the uptake of guidelines in this area have been [36].

Interestingly the overall health status variable was included in only three of the models (physical inactivity, smoking and high psychological distress) with higher odds for those respondents reporting fair/poor health. The variable that assessed anger with current health status was also included in these three models in addition to the fruit and vegetable model. While it is acknowledged that anger is associated with many chronic diseases including heart disease [37], depression and other mental health problems [38], diabetes [39], and arthritis [40] the relationship with risk factors has not been explored and highlights an area for further research.

One of the major strengths of this study is the use of a large randomly selected sample of the Australian population. The large sample size allows for greater generalisation of results. The weaknesses of this study include the cross-sectional nature of the data collection with the consequent inability to determine direction of effect. The reliance on self-report for some of the assessed variables is vulnerable to social desirability or other biased responses and is also a weakness of this study. In addition, sampling by telephone directory is likely to under sample some groups in the community. The study only involves community living adults and as such people living in supported accommodation such as aged care facilities would be missed from the sample. The response rate of nearly $44 \%$ is acceptable for this type of survey but the potential for survey non-response bias is acknowledged. Response rates are declining in surveys based on all forms of interviewing $[41,42]$ as people have become more active in protecting their privacy. The growth of telemarketing has disillusioned the community and diminished the success of legitimate social science research by means of telephone-based surveys. In addition, the increased use of mobile telephones and decreased use of land-lines could result in an under-representation of younger respondents (with younger persons more likely to have mobile telephones only and hence be excluded from sampling frames based on listed telephone numbers). Up to $5 \%$ of telephone calls made were on mobile telephones (those that are listed in the EWP or those that are obtained when contact is made with the household).

Other weaknesses of the study are the lack of validation of some of the variables and the fact that these data elements were collected with a range of other variables that were not included in the analysis. This exclusion of these other variables did not allow for consideration of potential confounders. Only using questions pertaining to fruit and vegetable consumption to represent a balanced diet could also be seen as a weakness of the study. Notwithstanding these weaknesses, the overall prevalence estimates obtained from this survey are in line with state and national estimates indicating a non-biased sample.

\section{Conclusion}

Research is needed on the relationship between worry, perceived risk and actual behaviours rather than behavioural intentions [8] and this study has assisted in this development. Further research could develop this relationship between perceived risk, worry and actual behavioural by assessing intentions to change.

While there is a known cluster of risk factors [43] the characteristics associated with those who worry about the risk factor, as shown in this study, vary remarkably. As argued by Baron et al. [5] some people over-worry or worry about the wrong aspects and this study has shown that much of the population are worrying about the health affect of a behaviour they are actually undertaking adequately. This research has determined a unique way of providing evidence for health promotion campaigns centred on reducing inappropriate health behaviours.

\section{Abbreviations}

BMI: Body Mass Index; CATI: Computer Assisted Telephone Interviewing; EWP: Electronic White Pages; K10: Kessler 10; OR: Odds ratio; SPSS: Statistical Package for Social Sciences.

\section{Competing interests}

The authors declare that they have no competing interests.

\section{Authors' contribution}

AWT and KP were responsible for the conception and design of the study. SF conducted the analysis. AWT drafted the manuscript. All authors had full access to the reports and tables and provide advice on analysis and interpretation of data. All authors critically reviewed the draft versions and approved the final version of the manuscript. 


\section{Acknowledgement}

This work was supported by a Department of Health and Ageing Sharing Care Health Initiative Grant

\section{Author details}

${ }^{1}$ Population Research and Outcome Studies, University of Adelaide, Level 3 122 Frome Street, Adelaide, South Australia 5000, Australia. ${ }^{2}$ Associate Professor Kay Price, School of Nursing and Midwifery, University of South Australia-City East Campus, GPO Box 2471, Adelaide, SA 5001, Australia.

Received: 30 April 2012 Accepted: 5 February 2013

Published: 8 February 2013

\section{References}

1. Armitage CJ, Connor M: Social cognition models and health behaviour: a structured review. Psychol Health 2000, 15:173-189.

2. Cameron LD, Reeve J: Risk perceptions, worry, and attitudes about genetic testing for breast cancer susceptibility. Psychol Health 2006, 21(2):211-230

3. Rose JP: Are direct or indirect measures of comparative risk better predictors of concern and behavioural intentions? Psychol Health 2010, 25(2):149-165.

4. Purdie N, McCrindle A: Self-regulation, self-efficacy and health behavior change in older adults. Educ Gerontol 2002, 28:379-400.

5. Baron J, Hershey JC, Kunreuther H: Determinants of priority for risk reduction: the role of worry. Risk Anal 2000, 20(4):413-427.

6. Kaptein AA, van Korlaar IM, Camerson LD, Vossen CY, van der Meer FLM, Rosendaal FR: Using the common-sense model to predict risk perception and disease-related worry in individuals at increased risk for venous thrombosis. Health Psychol 2007, 26(6):807-812.

7. Myers JR, Henderson-King DH, Henderson El: Facing technological risks: the importance of individual differences. J Res Pers 1997, 31:1-20.

8. Schmiege SJ, Bryan A, Klein WMP: Distinctions between worry and perceived risk in the context of the theory of planned behaviour. J App Soc Psychol 2009, 39(1):95-119.

9. Sjoberg L: Worry and risk perception. Risk Anal 1998, 18(1):85-93

10. Cameron LD, Diefenbach MA: Responses to information about psychosocial consequences of genetic testing for breast cancer susceptibility: Influences of cancer worry and risk perceptions. J Health Psychol 2001, 6(1):47-59.

11. de Hoog N, Strobe W, de Wit JBF: Pers Soc Psychol B 2005, 31(24):24-33.

12. Smerecnik CMR, Mesters I, de Vries NK, de Vries H: Alerting the general population to genetic risks: the value of health messages communication the existence of genetic risk factors for public health promotion. Health Psychol 2009, 28(6):734-745.

13. Das EHHJ, de Wit JBF, Stroebe W: Fear appeals motivate acceptance of action recommendations: evidence for a positive bias in the processing of persuasive messages. Pers Soc Psychol B 2003, 29(5):650-664.

14. University of South Australia: People with chronic disease and the influence of trial and error practices as a self-care strategy: a novel approach Summary of qualitative data. 2010. Downloaded from http://www.unisa.edu.au/nur/ research/projects/chronic disease/default.asp (accessed 27/10/2011).

15. Donaldson C: Marketing Health, influencing behaviour. J R Soc Promot Health 2008, 128(4):152-153.

16. Wakefield MA, Loken B, Hornik RC: Use of mass media campaigns to change health behaviour. Lancet 2010, 376:1261-1271.

17. Verbeke W: Impact of communication on consumers' food choices. Proc Nutr Soc 2008, 67:281-288.

18. Grant JF, Chittleborough CR, Taylor AW, Dal Grande E, Wilson DH, Phillips PJ, Ruffin R, North West Adelaide Health Study team: The North West Adelaide Health Study: methodology and baseline self-reported and biomedical results of a cohort along a chronic disease and risk factor continuum. Epidemiol Perspect Innovat 2006, 3:4. 12 April 2006.

19. Health N, Council MR: Dietary guidelines for Australian Adults. Canberra: Commonwealth of Australia; 2003

20. Health N, Council MR: Australian alcohol guidelines: Health risks and Benefits. Canberra: NHMRC; 2001.

21. World Health Organization: Obesity: Preventing and managing the global epidemic. Geneva: WHO; 2000

22. Kessler R, Mroczek D: Final versions of our non-specific psychological distress scale. Michigan: Institute for Social Research, University of Michigan; 1994.
23. Daly A, Taylor A: Population Health Monitoring and Surveillance, Question development field testing - Field testing 1 report (Asthma, Demographic Characteristics and Diabetes). 2003. http://www.nphp.gov.au/catitrg/ documents/fieldtest01rpt.pdf.

24. Price K, Van Loon A, Taylor A, Kralik D: People with chronic disease and the influence of trial and error practices as a self-care strategy: a novel approach: summary of qualitative data. Adelaide: University of South Australia; 2010 ISBN 978-0-9807778-0-2.

25. Hosmer DW, Lemeshow S: Applied Logistic Regression. New York, NY: J Wiley and Sons; 1989.

26. Resnicow K, Davis R, Zhang N, Tolsma D, Calvi J, et al: Tailoring a fruit and vegetable intervention on ethcnic identity: results of a randomised study. Health Psychol 2009, 28:394-403.

27. Hagger MS: Personality, individual differences, stress and health. Stress and Health. 2009, 25:381-386.

28. Anderson $R$, Anderson D, Hurst C: Modeling factors that influence exercise and dietary change among midlife Australian women: results form the Helathy Aging of Women Study. Maturitas 2010, 67:151-158.

29. Shi HJ, Nakamura K, Takano T: Health values and health-informationseeking in relation to positive change of health practice among middleaged urban men. Prev Med 2004, 39:1164-1171.

30. Hooker S, Harmon B, Burroughs EL, Rheaume CE, Wilcox S: Exploring the feasibility of a physical activity intervention for midlife African American men. Health Educ Res 2011, 26(4):732-738.

31. Laaksonen M, Rahkonen O, Karvonen S, Lahelma E: Socioeconomic status and smoking. Analysing inequalities with multiple indicators. Eur J Public Health 2005, 15(3):262-269.

32. Bauman A, Ma G, Cuevas F, Omar Z, Waqanivalu T, Phongsavan P, Keke K, Bhushan A: for the Equity and Non-communicable Disease Risk Factors Project Collaborative Group. Cross-national comparisons of socioeconomic differences in the prevalence of leisure-time and occupational physical activity, and active commuting in six Asia-Pacific countries. J Epidemiol Community Health 2011, 65(1):35-43.

33. Paeratakul S, Lovejoy JC, Ryan DH, Bray GA: The relation of gender, race and socioeconomic status to obesity and obesity comorbidities in a sample of US adults. Int J Obes 2002, 26(9):1205-1210.

34. Flocke SA, Antognoli E, Step MM, Marsh S, Parran T, Mason MJ: A teachable moment communication process for smoking cessation talk: description of a group randomized clinician-focused intervention. BMC Health Serv Res 2012, 12:109.

35. Goldstein MG, Whitlock EP, DePue J: Multiple behavioural risk factor interventions in primary care. Summary of research evidence. Am J Prev Med 2004, 27:61-79.

36. Green LW, Ottoson JM, Garcia C, Hiatt RA: Diffusion theory, and knowledge dissemination, uitilisation and intregation in public health. Annu Rev Public Health 2009, 30:151-174.

37. Laszlo K, Janszky I, Ahnve S: Anger expression and prognosis after a coronary event in women. Int J Cardiol 2010, 140:60-65.

38. Ahmed AO, Green BA, McCloskey MS, Berman ME: Latent structure of intermittent explosive disorder in an epidemiological sample. J Psychiatr Res 2010, 44(10):663-72.

39. Golden SH, Williams JE, Ford DE: Anger temperament is modestly associated with the risk of type 2 diabetes mellitus. The atherosclerosis risk in communities study. Psychoneuroendocrinology 2006, 31(3):325-332.

40. McCracken J, Lindner $\mathrm{H}$, Sciacchitano $\mathrm{L}$ : The mediating role of secondary beliefs: enhancing the understanding of emotional responses and illness perceptions in arthritis. J Allied Health 2008, 37(1):30-7.

41. Groves RM: Non-response rates and non-response bias in household surveys. Public Opin Q 2006, 70:646-675.

42. Curtin R, Presser $S$, Singer E: Changes in telephone survey non-repsonse over the past quater century. Public Opin Q 2005, 69:87-88.

43. Schuit AJ, van Loon JM, Tijhuis M, Ocke MC: Clustering of lifestyle risk factors in a general adult population. Prev Med 2002, 35:219-224.

doi:10.1186/1471-2458-13-120

Cite this article as: Taylor et al.: A survey to assist in targeting the adults who undertake risky behaviours, know their health behaviours are not optimal and who acknowledge being worried about their health. BMC Public Health 2013 13:120. 